\title{
Human Adipose Derived Stem Cells Exhibit Enhanced Liver Regeneration in Acute Liver Injury by Controlled Releasing Hepatocyte Growth Factor
}

\author{
Ja Sung Choi ${ }^{\mathrm{a}}$ Hyun Aae Ryu ${ }^{\mathrm{b}}$ Sae Hee Cheon ${ }^{\mathrm{s}}$ Sung-Whan Kim ${ }^{\mathrm{b}}$ \\ aDepartment of Internal Medicine, Catholic Kwandong University College of Medicine, International \\ St. Mary's Hospital, Incheon, South Korea, 'Department of Medicine, College of Medicine, Catholic \\ Kwandong University, Gangneung, South Korea, 'Department of Dental Hygiene, Masan University, \\ Masan, South Korea
}

\section{Key Words}

Growth factor • Mesenchymal stem cells • Regeneration • Liver cirrhosis

\begin{abstract}
Background/Aims: Although mesenchymal stem cells (MSCs) provide effective therapy for liver fibrosis, there are conflicting data regarding their marginal therapeutic effects. This study aimed to enhance the potential of hepatocyte regeneration in human adipose mesenchymal stem cells (ASCs) and investigate whether they have robust therapeutic efficacy in experimental liver fibrosis. Methods: ASCs were cultured with four cytokines (ASC-C), the expression of hepatogenic factors was detected by microarray, and the effects of conditioned medium (CM) from ASC-C on the activation of hepatic stellate cells were analyzed. The therapeutic effects and mechanism of liver fibrosis induced by thioacetamide (TAA) were determined after cell transplantation. Results: ASC-C exhibited high levels of hepatogenic (HGF, G-CSF), anti-apoptotic (IGFBP-2), and chemokine (IL-8) genes and increased expression of hepatocyte specific proteins. ASC-C CM inhibited the activation of hepatic stellate cells in vitro, and injection of ASC-C significantly delayed TAA-induced liver fibrosis and improved liver function and regeneration in vivo. In addition, human albumin-expressing ASC-C were observed in the livers of recipient animals. High levels of expression of HGF and its downstream signaling molecules, including p-38, were detected in the ASC-C-injected livers. Transplantation of ASC-C exerts anti-fibrotic effects and accelerates liver regeneration. Conclusion: Thus, ASC-C may be a novel candidate for the enhanced treatment of liver cirrhosis in clinical settings.
\end{abstract}




\section{Cellular Physiology Cell Physiol Biochem 2019;52:935-950 \\ \begin{tabular}{ll|l} 
and Biochemistry $10.33594 / 000000065$ & $\begin{array}{l}\text { Published online: } 10 \text { April } 2019 \\
\text { Cell Physiol Biochem Press GmbH\&Co. KG }\end{array}$ \\
\hline
\end{tabular} \\ Choi et al.: Generation of Induced Hepatogenic Stem Cells}

\section{Introduction}

Chronic hepatic injury and liver cirrhosis are mostly caused by exposure to many factors, such as hepatitis virus, drugs, xenobiotics and alcohol abuse, which lead to progressive fibrosis, hepatocellular carcinoma and organ failure [1]. To date, liver transplantation is the only effective treatment; however, limited donors and organ rejection are the main obstacles to effective treatment with transplantation.

Recently, stem cell therapy has been suggested as one of the promising therapeutic approaches to treat liver failure. In fact, adipose tissue-derived mesenchymal stem cells (ASCs) secrete high levels of hepatocyte regeneration-associated cytokines or growth factors, showing that the transplantation of stem cells can improve the function of damaged livers [2, 3].

Hepatocyte growth factor (HGF) has been demonstrated as a key factor responsible for the cytoprotective and regenerative potential of hepatocytes [4-6]. It is known that HGF stimulates the proliferation and migration of hepatic stem cells into the liver parenchyma, and it helps their differentiation into mature hepatocytes [7]. Recent reports showed that mesenchymal stem cells (MSCs) overexpressing HGF prevented liver failure and reduced mortality in rats [8].

The secretion of potent growth factors or cytokines and the proliferation of MSCs can be affected by growth factors, such as platelet-derived growth factor (PDGF), fibroblast growth factor-2 (FGF-2), epidermal growth factor (EGF) and insulin-like growth factor-1 (IGF-1), suggesting potential synergism in enhancing therapeutic efficacies [9-11]. In addition, FGF2-induced HGF secretion by adipose-derived stromal cells inhibits post-injury fibrogenesis through JNK signaling [12]. In this study, we found a novel stem cell culture condition that enhances the potential of anti-fibrosis and liver regeneration by ASCs and investigated its therapeutic mechanism in acute liver fibrosis.

\section{Materials and Methods}

\section{Cell culture}

Five different lines of human adipose MSCs (ASCs) were purchased from ATCC (Manassas, markers was examined by FACS. ASCs were maintained at $37^{\circ} \mathrm{C}$ under $5 \% \mathrm{CO}_{2}$ in culture medium [a-MEM with $10 \%$ fetal bovine serum (FBS), $100 \mathrm{U} / \mathrm{mL}$ of penicillin, and $100 \mathrm{mg} / \mathrm{mL}$ of streptomycin]. To enhance HGF expression, ASCs were cultured at $37^{\circ} \mathrm{C}$ under $5 \% \mathrm{CO}_{2}$ in culture medium [a-MEM with $2 \%$ fetal bovine serum (FBS), $100 \mathrm{U} / \mathrm{mL}$ of penicillin, and $100 \mathrm{mg} / \mathrm{mL}$ of streptomycin] containing cytokine cocktails including $20 \mathrm{ng} / \mathrm{ml}$ human vascular endothelial growth factor (VEGF)-A, $100 \mathrm{ng} / \mathrm{ml}$ human fibroblast growth factor (FGF)-2, $20 \mathrm{ng} / \mathrm{ml}$ human epidermal growth factor (EGF), and $20 \mathrm{ng} / \mathrm{ml}$ human insulin-like growth factor (IGF)-1 for 5 days. The human hepatic stellate cells (HSCs) LX-2 were purchased from Millipore (Temecula, CA, USA). HSCs were derived from healthy donors and characterized by immunocytochemistry such as Desmin (positive), GFAP (positive) and $\alpha$ SMA (negative).

All experimental protocol was approved by the institutional review board of Catholic Kwandong University. Written informed consent for all human subjects was provided by each donor. All experiments were performed in accordance with relevant guidelines and regulations.

Real-time polymerase chain reaction (PCR)

Quantitative real-time (qRT)-PCR assays were performed as previously described [13, 14]. Briefly, total RNA was isolated from cells using RNA-stat (Iso-Tex Diagnostics, Friendswood, TX, USA) according to a previously reported method [15]. The extracted RNA was subsequently reverse transcribed using TaqMan reverse transcription reagents (Applied Biosystems, Foster City, CA, USA) according to the manufacturer's instructions. The synthesized cDNA was subjected to qRT-PCR or reverse transcription (RT)-PCR using human/mouse-specific primers and probes. The RNA levels were quantitatively assessed using an ABI PRISM 7000 Sequence Detection System (Applied Biosystems). The relative mRNA expression normalized to 


\section{Cellular Physiology Cell Physiol Biochem 2019;52:935-950

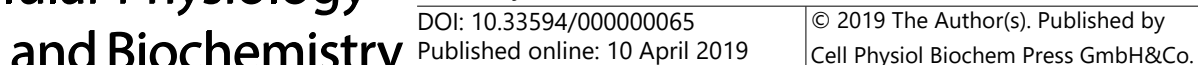 \\ Choi et al.: Generation of Induced Hepatogenic Stem Cells}

GAPDH expression was calculated. The primers used for qRT-PCR were as follows: HGF (Hs00300159_m1), M-CSF (Hs00174164_m1), G-CSF (Hs00738432_g1), SCF (Hs00241497_m1), LIF (Hs01055668_m1), IL-8 (Hs00174103_m1), IGFBP-2 (Hs01040719_m1), TNF- $\alpha$ (Hs00174128_m1) and GAPDH (Hs99999905_m1).

\section{Induction of liver fibrosis and cell transplantation}

Six-week-old female BALB/c nu mice were purchased from Koatech (Pyeongtaek, Korea). All experimental protocol was approved by the Institutional Animal Care and Use Committee of Catholic Kwandong University. The mice were intraperitoneally injected with $150 \mathrm{mg} / \mathrm{kg}$ thioacetamide (TAA; Sigma Chemicals, St Louis, MO, USA) two times a week for 4 weeks. After the induction of liver fibrosis (i.e., 1 week after TAA injection), cell transplantation was performed. Cells $\left(1 \times 10^{6}\right)$ were resuspended in normal saline and administered via the portal vein. The mice were randomly divided into three groups: sham (PBS) ( $\mathrm{n}=$ $10)$, ASC $(n=10)$ and ASC-cocktail (ASC-C) $(n=10)$. The sham group received $50 \mu$ l of normal saline. Liver tissues were collected 3 weeks after cell injection.

\section{Histological analyses and collagen detection}

The livers from nude mice were fixed with 4\% paraformaldehyde for 1 day and embedded in Tissue-Tek OCT compound (Sakura Fine Technical Co. Ltd., Japan). Sectioned ( $5 \mu \mathrm{m}$ thick) samples were stained with Harris hematoxylin solution (Sigma) for 2 minutes followed by eosin Y (Sigma, MO) for $20 \mathrm{sec}$. Collagen and hepatic fibrosis were assessed using a Sirius red/fast green collagen staining kit (Chondrex, Inc., Redmond, WA, USA) and Sirius red staining. Sectioned samples (10 $\mu \mathrm{m}$ thick) were fixed in Kahle's fixative for 30 minutes, and the sections were then stained in the dye solution for 30 minutes. The sections were rinsed with distilled water and incubated with a dye extraction buffer. Then, we collected the eluted dye solution and read the O.D. value at $540 \mathrm{~nm}$ and $620 \mathrm{~nm}$ with a spectrophotometer. Masson's trichrome staining was performed, and the areas of fibrosis were measured by MetaMorph software (Downingtown, PA). anti Ki-67 (1:200, Dako, Carpinteria, CA) and anti- proliferating cell nuclear antigen (PCNA ,1:100, Abcam) were used for cell proliferation assay. To measure capillary density and human albumin, tissues were stained with primary biotinylated IL (isolectin) B4 (1:250, Vector Laboratory, Burlingame, CA) and anti-human/antimouse albumin $(1: 200$, Abcam, Cambridge, MA) using a secondary antibody conjugated with streptavidinAlexa Fluor 488 or 555 (1:400, Invitrogen, Carlsbad, CA). TdT-mediated dUTP nick end labeling (TUNEL) assay was performed using a fluorescein in situ cell death detection kit (Roche Molecular Biochemicals, Mannheim, Germany). Nuclei (blue) were stained with DAPI.

\section{Immunoblot analysis}

Western blot assays were performed using a previously described method [16, 17]. Briefly, protein extracts (100 $\mu$ g each) were separated on 8\% SDS-PAGE gels (Bio-Rad Laboratories) and electrotransferred onto PVDF membranes (GE Healthcare). The specimens were probed with antibodies against the following: alpha-fetoprotein (AFP), albumin (ALB), cytokeratin (CK)-18, CK-19, $\alpha$-smooth muscle actin ( $\alpha$-SMA) and $\beta$-actin (Santa Cruz Biotechnology, Inc.). The membranes were washed and incubated with horseradish peroxidase-conjugated secondary antibody, and the signal was detected using an LAS-3000 chemidoc system (Fujifilm, Japan).

\section{Assessment of liver functions}

Blood samples were collected from each group of nude mice and centrifuged, and serum samples were obtained 1 week before cell injection and 1, 2 and 3 weeks after cell injection. The serum samples were tested for liver injury markers such as aspartate aminotransferase (GOT/AST), alanine aminotransferase (GPT/ALT), ammonia and bilirubin by a FUJIFILM DRI-CHEM 3500 machine (Tokyo, Japan).

\section{Statistical analysis}

All data are presented as the mean \pm SD. Statistical analyses were conducted using Student's $t$-test for comparisons between 2 groups and ANOVA with Bonferroni's multiple comparison test using SPSS v11.0. The data with $\mathrm{P}<0.05$ were considered statistically significant. 


\section{Results}

Cell proliferation and hepatogenic characteristics of cytokine-induced human ASCs

To enhance the hepatogenic potential of ASCs, we tested several cytokine combinations. We designed a candidate cytokine combination with FGF-2, IGF-2, EGF and VEGF-A and tested whether it promoted the hepatogenic property of ASCs. First, to examine the effect of cell proliferation, ASCs were cultured for 5 days. ASCs without cytokine treatment were used as the control. In addition, we used FGF-2 (20 ng/ml)-treated ASCs (ASC-b) for 5 days as the positive control, as FGF-2 enhances the hepatogenic property of rat-derived ASCs [18]. Interestingly, ASCs treated with the cytokine cocktail (ASC-C) were highly proliferative compared with the FGF-2-treated or the untreated ASCs (Fig. 1A and 1B). In line with a previous report, FGF-2 was found to be the key factor in the cytokine cocktail for promoting HGF secretion (Supplementary Fig. 1A and 1B - all supplementary material available online at www.cellphysiolbiochem.com), and an extracellular signal-regulated kinase (ERK)

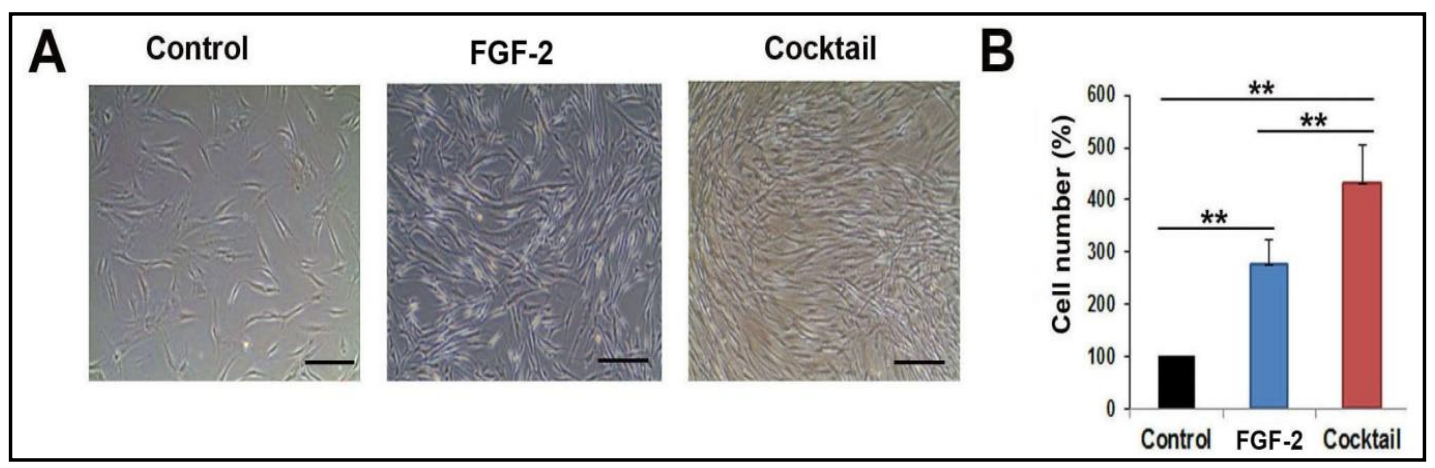

Fig. 1. Cell proliferation analysis. (A) Representative image of ex vivo expanded ASCs after incubation with FGF-2 and a cytokine cocktail for 5 days. (B) Comparison of the total number of ASCs after incubation with cytokines for 5 days. ${ }^{* *} \mathrm{p}<0.01 ; \mathrm{n}=5$ per group. $\mathrm{Bar}=100 \mu \mathrm{m}$.

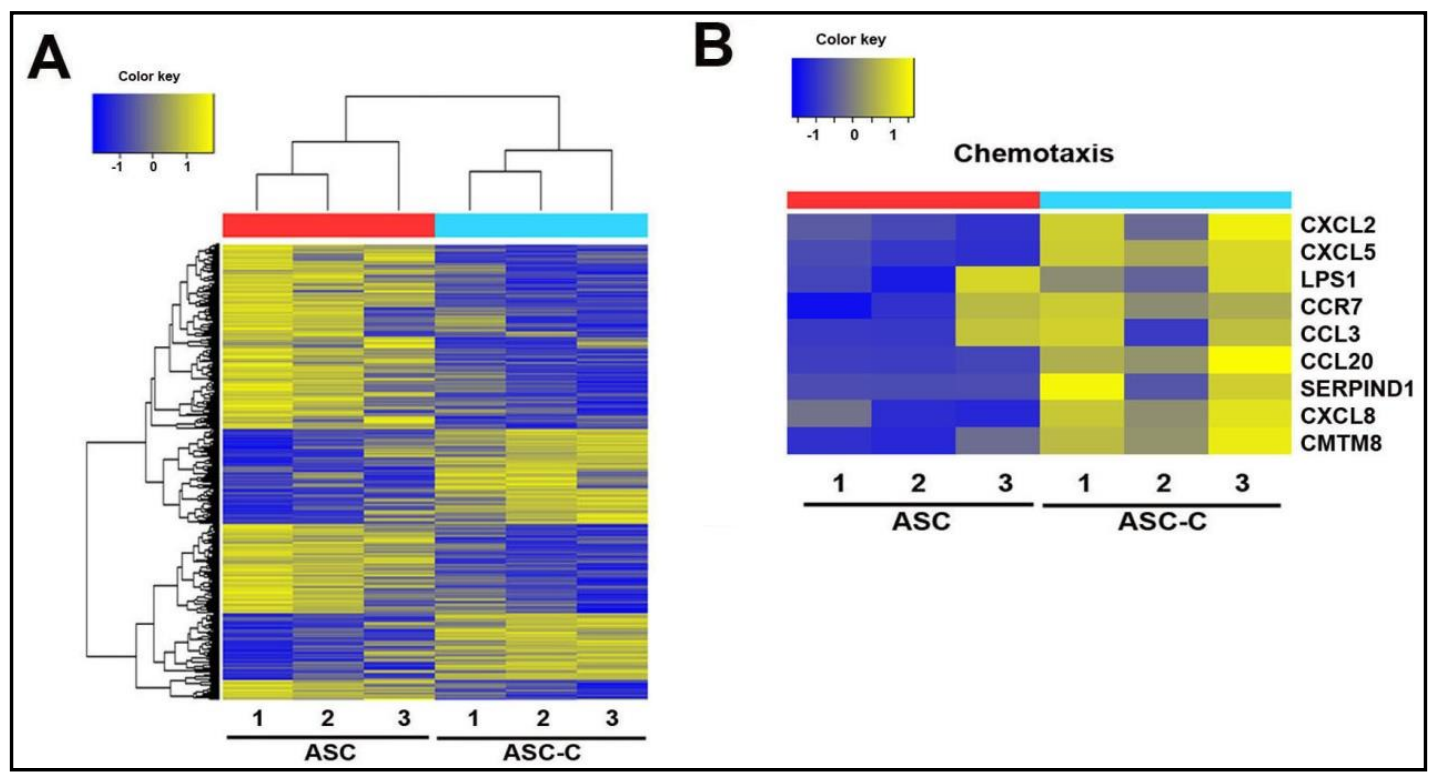

Fig. 2. Cell proliferation and global gene expression patterns of ASC-C and ASCs. Untreated ASCs were used as controls. (A) Global gene expression profiles of three lines of ASCs and ASC-C. The results of hierarchical clustering analysis represented as a heat map where each row reflects a probe set. Yellow signifies increased expression, and blue signifies decreased expression. (B) Heat map of chemotaxis as a biological process. (C) Chemotaxis as a significantly regulated process in ASC-C compared with ASCs. 
inhibitor (U0126) significantly decreased the expression of HGF in ASCs (Supplementary Fig. 1C). These results indicate that FGF-2 enhanced the expression of HGF through the ERK signaling pathway. In addition, we did not observe any remarkable changes in the spindle fibroblast-like morphology and surface expression of representative MSC markers after cytokine treatment of ASCs (Supplementary Fig. 2A-2E).

\section{ASC-C exhibit upregulated hepatogenic and chemotactic genes}

To explore the characteristics of ASC-C in detail, we investigated their global gene expression profile (30,606 probe sets on the arrays) using microarray analysis (Fig. 2A). Three ASC lines without cytokine treatment were used as controls, and three cytokine cocktail-induced ASC lines were tested. Interestingly, we found that the ASC-C exhibited higher levels of gene expression of insulin-like growth factor-binding protein (IGFBP)-2 (50.3-fold), HGF (26.1-fold) and granulocyte-colony stimulating factor (G-CSF), also known as colony-stimulating factor 3 (CSF3) (23.3-fold) than the control ASCs (Supplementary Table 1). Intriguingly, gene ontology (biological process) analysis revealed that a chemotaxisrelated gene set was highly enriched in the ASC-C (Fig. 2B and Table 1).

Next, to confirm the microarray data, we performed qRT-PCR. In line with the microarray data, the ASC-C significantly expressed multiple factors associated with essential hepatocyte regeneration, including HGF, tumor necrosis factor (TNF)- $\alpha$, stem cell factor (SCF) and G-CSF, compared with ASCs (Fig. 3). Other minor regenerative or cytoprotective factors, such as leukemia inhibitory factor (LIF), interleukin (IL)-8 and IGFBP-2, were also highly expressed by ASC-C compared with ASCs or ASC-b.

\section{ASC-C exhibit expression of hepatocyte-specific genes and proteins}

To investigate whether ASC-C possess hepatocyte-like properties, we analyzed their hepatocyte-specific gene expression patterns by microarray analysis. We randomly chose 41 hepatocyte-related genes and analyzed the microarray data. The results demonstrated that 15 hepatocyte-related genes were upregulated in ASC-C compared with those in ASCs

Table 1. Gene ontology result. Significantly up-regulated biological process in ASC-C compared with ASCs

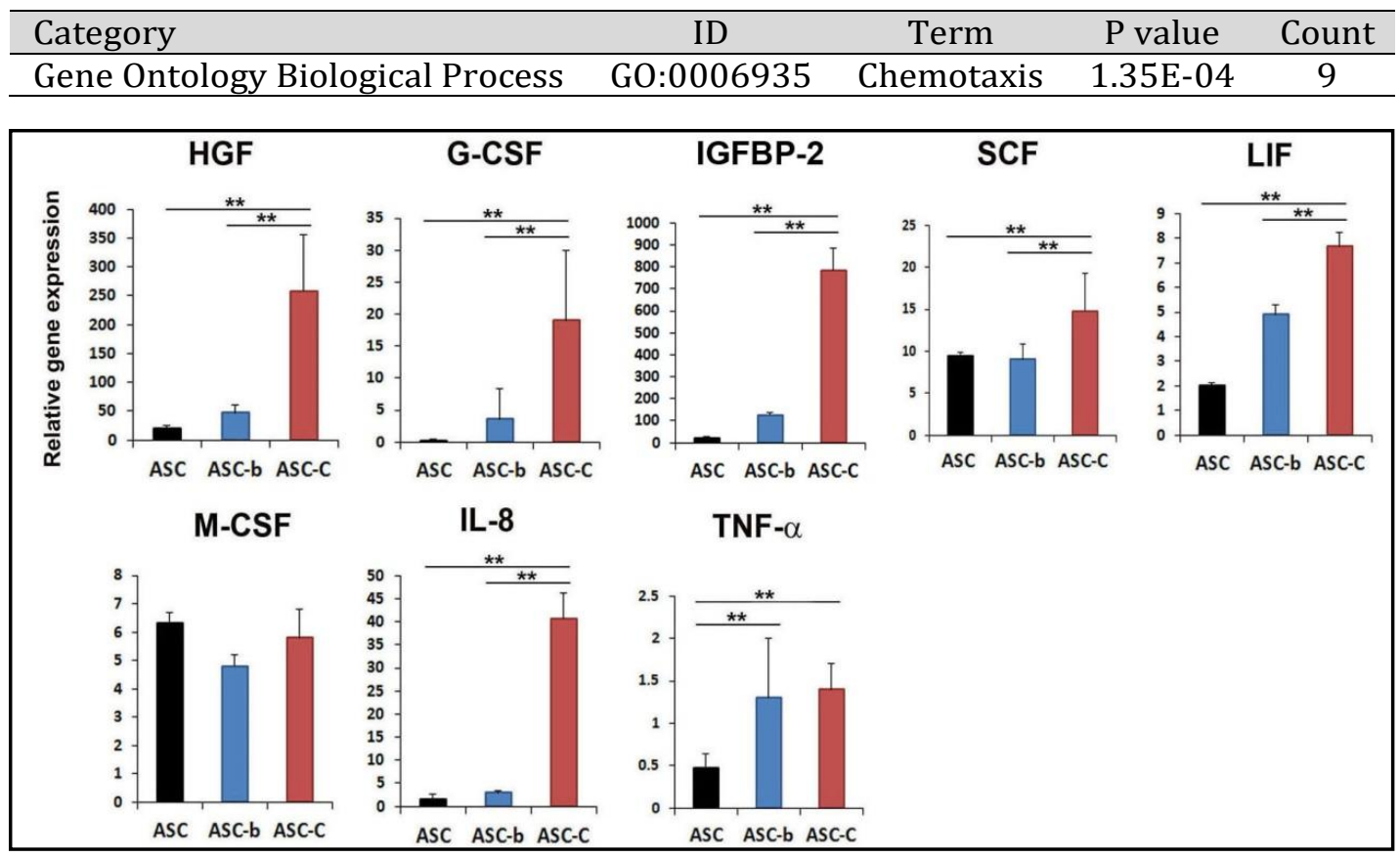

Fig. 3. The expression patterns of multiple hepatogenic and chemotactic factors were measured by qRT-PCR. The data are presented as fold change compared with the mononuclear cell group. Individual values were normalized to glyceraldehyde 3-phosphate dehydrogenase (GAPDH). $\mathrm{n}=4$ per group. ${ }^{*} \mathrm{p}<0.05$; $^{* *} \mathrm{p}<0.01$. 


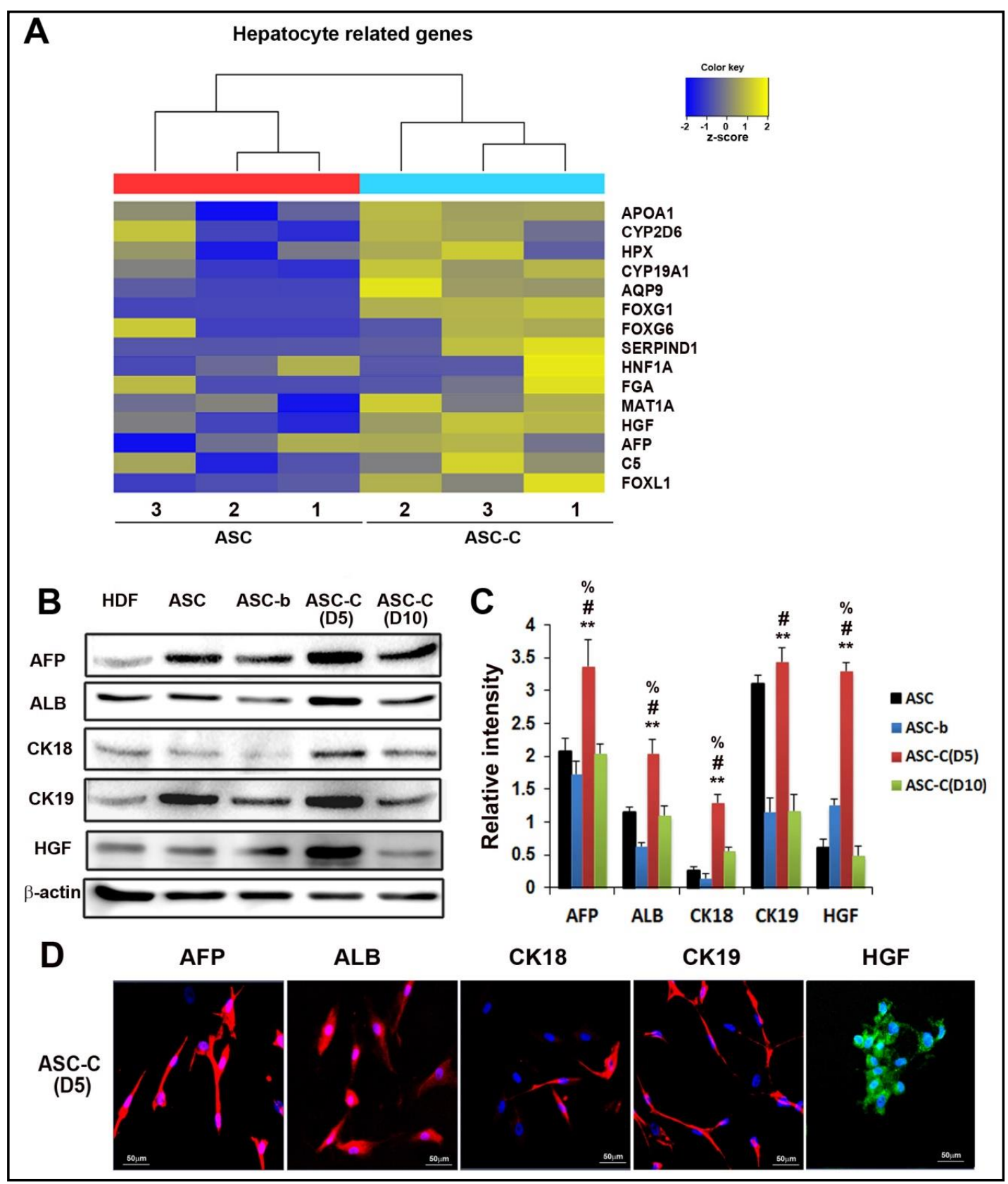

Fig. 4. Hepatocyte characteristics of ASC-C. (A) The results of hierarchical clustering analysis represented as a heat map of the expression level of 15 hepatocyte-related genes. (B) Western blot results of the expression of 5 representative hepatocyte-specific proteins. Protein levels of AFP, ALB and HGF correlated with the microarray data. (C) Quantitative analysis of western blot results. The individual values were normalized to $\alpha$-actin. $\mathrm{n}=4$ per group. ${ }^{* *} \mathrm{p}<0.01$ vs. ASC-b; ${ }^{*} \mathrm{p}<0.01$ vs. ASC-C (D-10); ${ }^{\%} \mathrm{p}<0.01$ vs. ASCs. (D) Immunocytochemistry results of ASC-C. DAPI=4, 6-diamidino-2-phenylindole (Blue fluorescence).

(Fig. 4A and Supplementary Table 2). Next, we confirmed the expression of representative hepatocyte-specific proteins by western blotting and immunocytochemistry. Intriguingly, ASC-C (day 5) highly expressed alpha-fetoprotein (AFP), albumin (ALB), cytokeratin (CK) 18, CK19 and HGF compared with ASCs and ASC-b (Fig. 4B and 4C). In line with western blotting results, immunocytochemistry results revealed that ASC-C (day 5) exhibited AFP, ALB, CK18, CK19 and HGF (Fig. 4D). These results indicate that ASC-C were partially differentiated into hepatocyte-like cells and possess hepatocyte progenitor-like properties. 
Conditioned medium (CM) from ASC-C decreases the activation of HSCs in vitro

The effect of MSC-CM on $\alpha$-smooth muscle actin (SMA) expression of primary human hepatic stellate cells (HSCs) was measured. HSCs were treated with control medium, TGF- $\beta$ (positive control), ASC-CM and ASC-C-CM together with TGF- $\beta$ for 5 days and analyzed by dot blotting (Fig. 5A and 5B). Quantification of $\alpha$-SMA levels demonstrated that HSCs cultured with MSC-C-CM showed significantly lower levels of $\alpha$-SMA compared with HSCs cultured with the vehicle (positive control) and ASC-CM (Fig. 5C), indicating the neutralization of the activation induced by TGF- $\beta$.

\section{Transplantation of ASC-C ameliorates acute liver injury}

To investigate the therapeutic effect of cytokine-induced ASCs, we transplanted $5 \times 10^{5}$ cells into nude mice via the portal vein 1 week after induction of acute liver failure with TAA. Three weeks after cell injection, the liver tissues were evaluated (Fig. 6A). Morphological analysis showed that the contour of the liver surface from PBS- and ASC-treated mice was markedly irregular compared with that of the ASC-C-treated mice (Fig. 6B and Supplementary Fig. 3). H\&E examination of the livers also showed that the PBS- and ASC-treated mice displayed a distorted hepatic architecture compared with the ASC-C treated mice (Fig. 7A). We also assessed hepatic collagen content after cell transplantation. The hepatic collagen content of the ASC-C-treated mice was significantly lower than that of the PBS- and ASCtreated mice (Fig. 7B). Decreased collagen content in liver indicates that there has been an active extracellular matrix (ECM) remodeling. Thus we measured mRNA level in liver tissues after cell injection using representative ECM molecules. Matrix metalloprotease (MMP) is one of the key regulators of ECM glycoprotein and remodeling [19]. In present study, MMP13 was upregulated in ASC-C injected liver tissue (Supplementary Fig. 4A and 4B).

Fig. 5. Effect of ASC-C conditioned medium (CM) on the activation of hepatic stellate cells. (A-B) Western blot results of total protein of LX2 cells treated with TGF- $\beta$ and $\mathrm{CM}$ from ASCs, ASC-C and untreated cells (Veh $=$ Vehicle) for 5 days and untreated LX2 cells (C $=$ control). (C) Quantitative analysis of western blot results. The individual values were

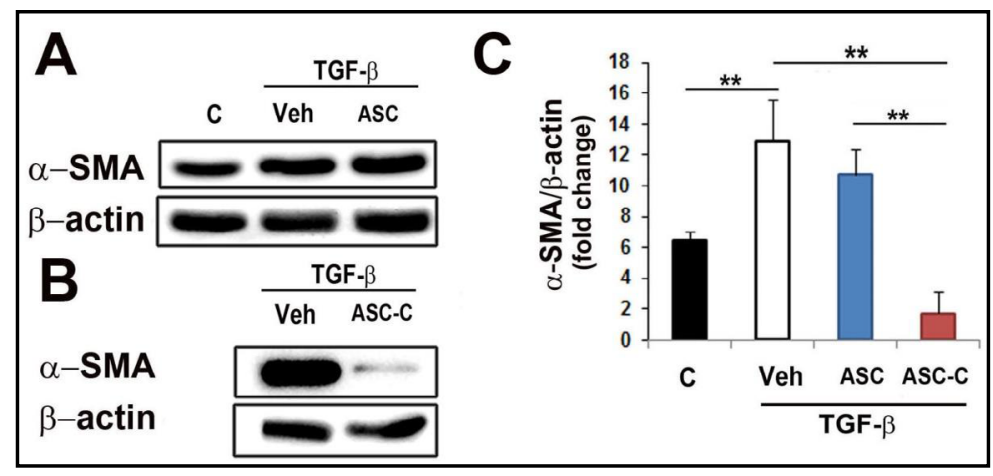
normalized to $\alpha$-actin. $\mathrm{n}=4$ per group. ${ }^{* *} \mathrm{p}<0.01$.

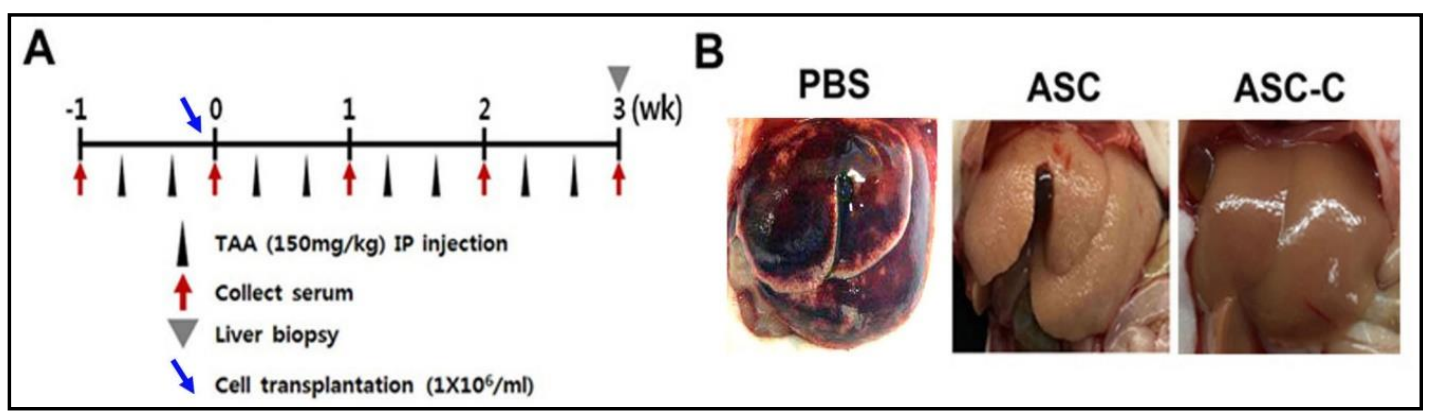

Fig. 6. In vivo therapeutic effects of ASC-C in acute liver failure in nude mice. (A) Schematic representation of the procedure for the induction of acute liver failure, cell injection and the collection of specimens. (B) Representative morphology of the liver after the induction of acute liver failure and cell injection. The surface contour of the livers of PBS- or ASCs-treated mice was markedly irregular compared with that of the ASC-C-treated mice. 


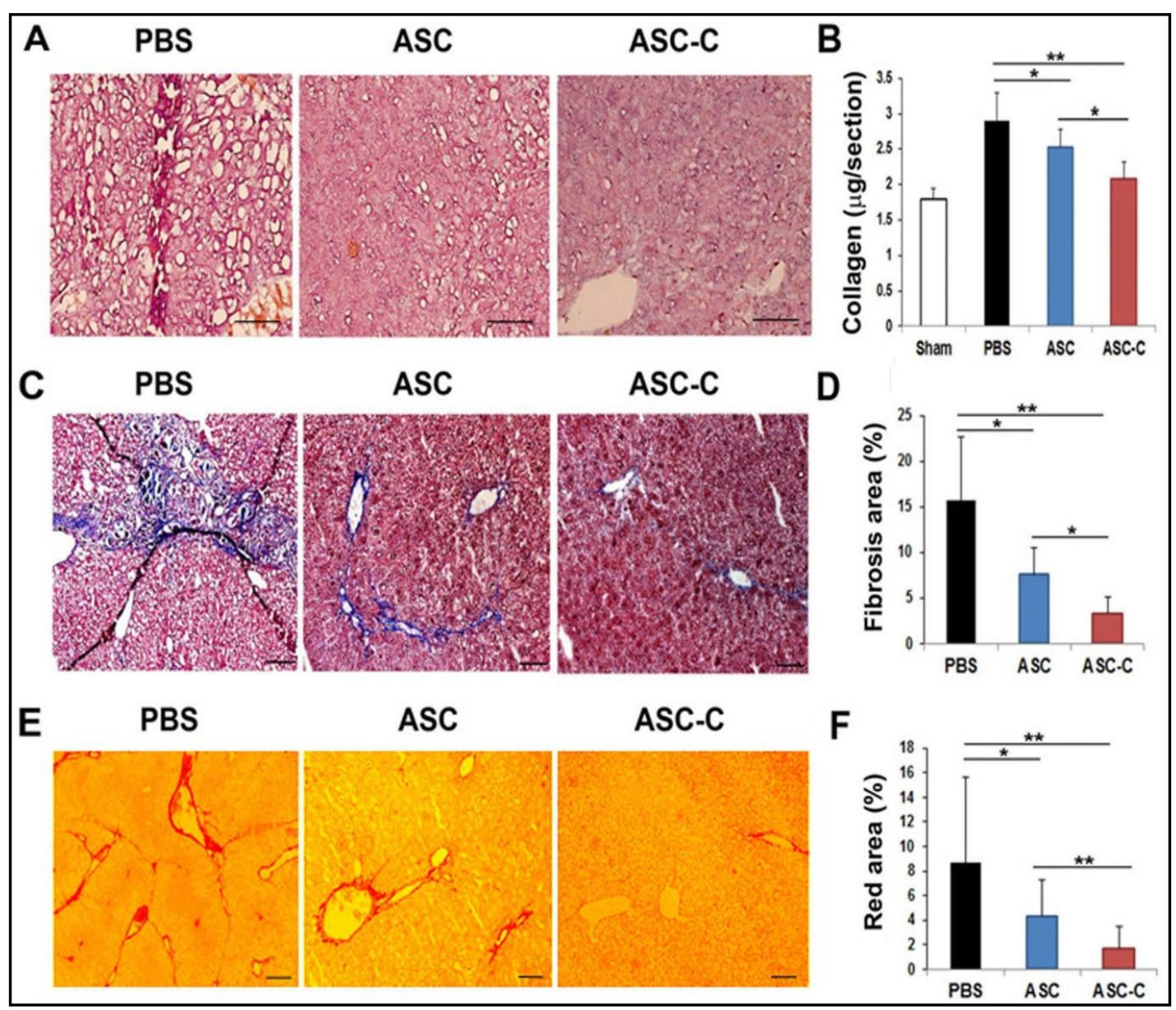

Fig. 7. In vivo therapeutic effects of ASC-C in acute liver failure mice model. (A) Representative H\&E staining of liver sections after cell transplantation. PBS- and ASC-treated livers showed a distorted hepatic architecture compared with ASC-C-treated livers. Bar $=100 \mu \mathrm{m}$. (B) Quantitative analysis of collagen from liver tissues. The hepatic collagen content was measured using Sirius red/fast green collagen staining. Sectioned samples were fixed in Kahle's fixative, and the sections were stained in dye solution and mixed with a dye extraction buffer. The dye solutions were collected and their O.D. values were read by a spectrophotometer. $\mathrm{n}=6$ per group. ${ }^{* *} \mathrm{p}<0.01 ;{ }^{*} \mathrm{p}<0.05$. (C) Representative images of fibrosis by Masson's trichrome (MT) staining after cell injection. Bar $=100 \mu \mathrm{m}$. (D) Quantitative analysis of the fibrotic area by MT staining. $\mathrm{n}=6$ per group. ${ }^{* *} \mathrm{p}<0.01 ;{ }^{*} \mathrm{p}<0.05$. (E) Representative images of Sirius red staining after cell injection. (F) Quantitative analysis of the area of hepatic fibrosis by Sirius red staining. $n=6$ per group. ${ }^{* *} \mathrm{p}<0.01 ;{ }^{*} \mathrm{p}<0.05$. Bar $=100$ $\mu \mathrm{m}$.

Next, to examine hepatic anti-fibrosis effects after cell injection, we conducted Masson's trichrome and Sirius red staining. The staining results also revealed that ASC-C treatment significantly reduced fibrosis compared with treatment with PBS or ASCs (Fig. 7C-7E and 7F). In addition, we also investigated stellate cell activation in liver after cell injection. Interestingly, $\alpha$-SMA level in vivo was highly reduced in ASC-C treated group compared with treatment with PBS or ASCs (Fig. 8A and 8B), suggesting low stellate cell activation.

\section{Transplantation of ASC-C improves liver function}

Next, to clarify the therapeutic effect from the changes in hepatic function after cell injection, we performed biochemical analysis using serum from mouse blood. At 2 weeks after ASC-C treatment, the concentration of GPT/ALT, GOT/AST, and ammonia was significantly decreased compared with ASC or PBS treatment (Fig. 9A-9C). Likewise, total bilirubin was 
Fig. 8. In vivo $\mathrm{t} h$ e ra p e u t i c mechanism effects of ASC-C. (A) Representative images of Western blot results in cell injected liver. (B) Quantitative analysis of western blot results. The individual values were normalized to $\alpha$-actin. $\mathrm{n}=4$ per group. ${ }^{* *} \mathrm{p}<0.01{ }^{* *} \mathrm{p}<0.05$.

also significantly decreased in the ASC-C-treated group compared with the ASC- or PBS-treated groups (Fig. 9D). We also measured the differences in body and liver weight between the groups after cell injection. The ASCC-treated mice also showed higher liver/body weight at 3 weeks after injection than the ASC-, ASC-b- or PBS-treated mice (Fig. 9E). These data indicate that ASC-C have a beneficial influence on promoting liver recovery.

\section{Transplantation of ASC-C promotes liver regeneration}

To elucidate the mechanisms of the amelioration of liver damage by cell transplantation, the proliferation of hepatocytes and capillary density in the liver were evaluated. Histological observations revealed significantly higher numbers of Ki-67-positive cells (Fig. 10A and 10B) or PCNA-positive hepatocytes in ASC-C-treated mice than in ASC- or in PBS-treated mice (Fig. 10C and 10D). Capillary density was also
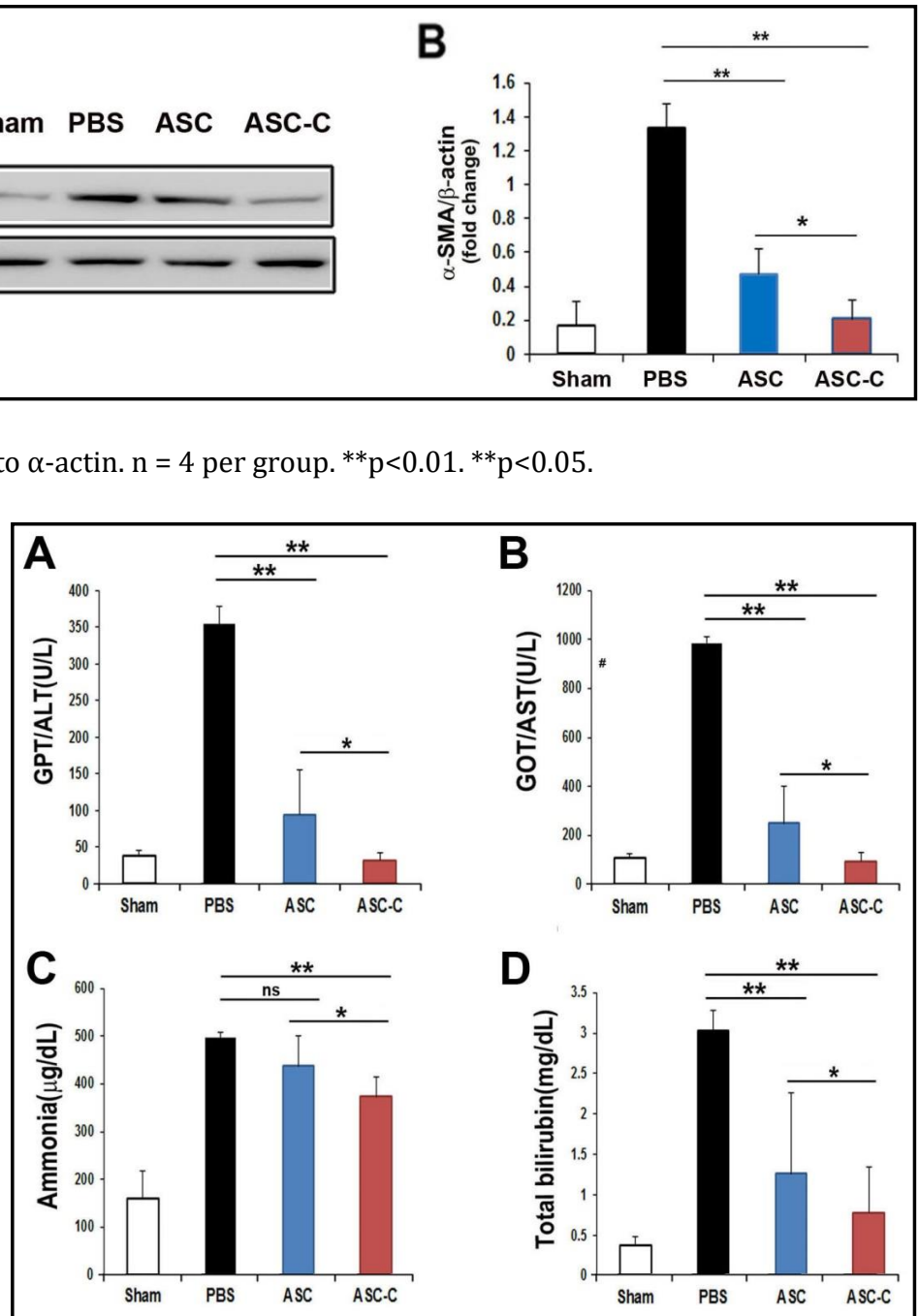

Sham PBS ASC ASC-C

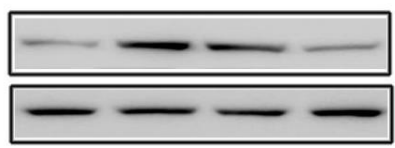

E

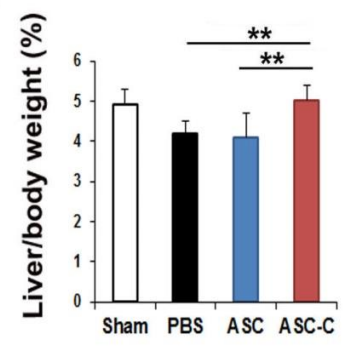

Fig. 9. Biochemical and body/liver weight analyses after cell transplantation. (A-D) The concentrations of GPT/ALT, GOT/AST, ammonia and total bilirubin in the serum at 3 weeks after cell injection were measured in nude mice. ${ }^{* *} \mathrm{p}<0.01 ;{ }^{*} \mathrm{p}<0.05 ; \mathrm{n}=10$ per group. ns $=$ not significant. (E) Liver/body weight at 3 weeks after cell injection. $*^{*} \mathrm{p}<0.01 ; \mathrm{n}=10$ per group. significantly higher in the ASC-C-treated livers than in the ASC- or PBS-treated livers (Fig. 10E and 10F). The number of apoptotic cells and hepatocytes in liver tissues measured by terminal deoxynucleotidyl transferase dUTP nick end labeling (TUNEL) assay was lowest in the ASC-C-injected mice 


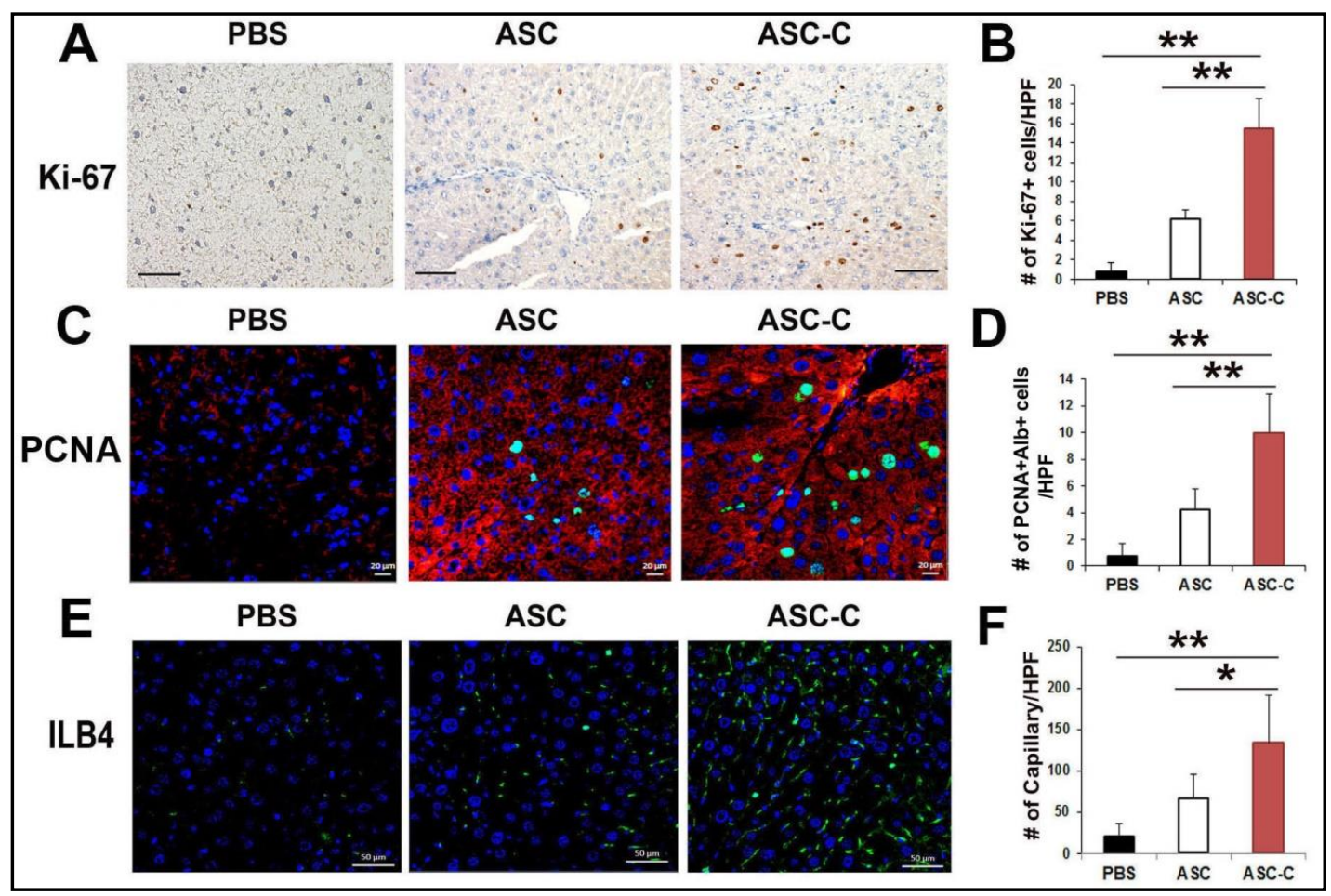

Fig. 10. ASC-C promote liver regeneration. (A) Representative images of Ki-67-positive cells in liver tissues by immunohistochemistry. The brown colored nuclei (arrow) indicate the Ki-67-positive hepatocytes. Bar $=100 \mu \mathrm{m}$. (B) Quantitative analysis of Ki-67 staining. ${ }^{* *} \mathrm{p}<0.01 ; \mathrm{n}=7$ per group. HPF = high power field. (C) Representative images of PCNA (green) and anti-mouse albumin (red)-positive hepatocytes in liver tissues by immunohistochemistry. Bar $=20 \mu \mathrm{m}$. (D) Quantitative analysis of PCNA staining. ${ }^{* *} \mathrm{p}<0.01 ; \mathrm{n}=7$ per group. (E) Representative images of capillary density in liver tissues after cell injection. Immunohistochemistry was performed by staining for IL-B4, an endothelial marker. Bar $=20 \mu \mathrm{m}$. (F) Quantitative analysis of the number of capillaries. ${ }^{* *} \mathrm{p}<0.01 ; \mathrm{n}=7$ per group.

Fig. 11. In vivo differentiation of ASC-C. (A) Engraftment of ILB4-expressing ASC-C (arrow) in the perivascular area of the liver. (B) Engraftment of human albuminexpressing ASC-C (arrows) in the liver.

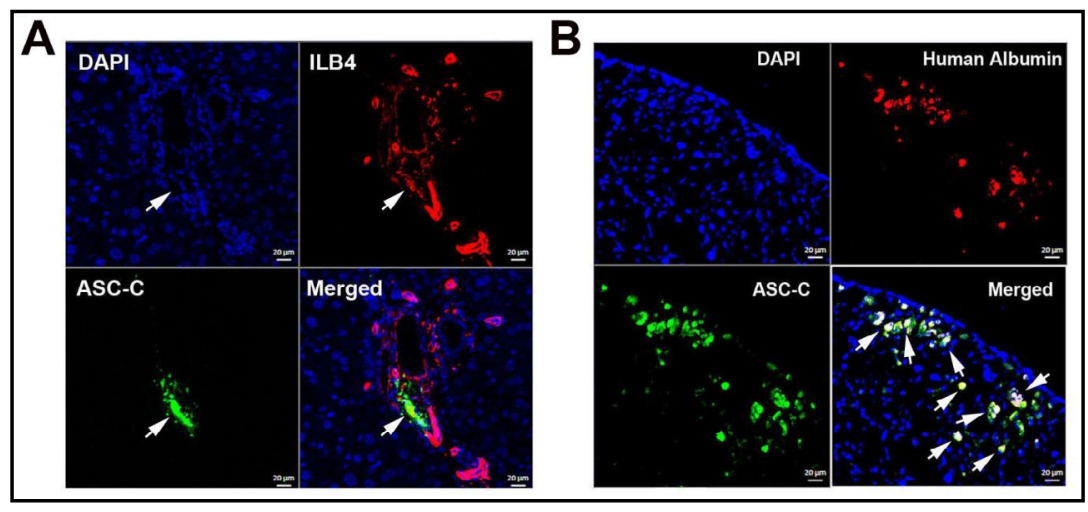

(Supplementary Fig. 5A - 5D). These results indicate that humoral factors such as HGF, IGBP2, SCF, G-CSF and IL-8 derived from ASC-C might promote liver regeneration by inducing hepatocyte proliferation or angiogenesis.

Next, to determine the fate of the transplanted ASC-C, we performed histological analysis using the blood vessel marker IL (isolectin) B4 and human albumin. To trace the injected cells, we transplanted GFP-expressing ASC-C (Supplementary Fig. 2F) into nude mice with acute liver fibrosis via the portal vein. Histology data in liver tissue revealed that some of the ASC-C engrafted in the peri-vascular area express ILB4 (Fig. 11A) and some of the cells engrafted in the peri-portal or the peri-sinusoid area express human albumin (Fig. 11B). We 


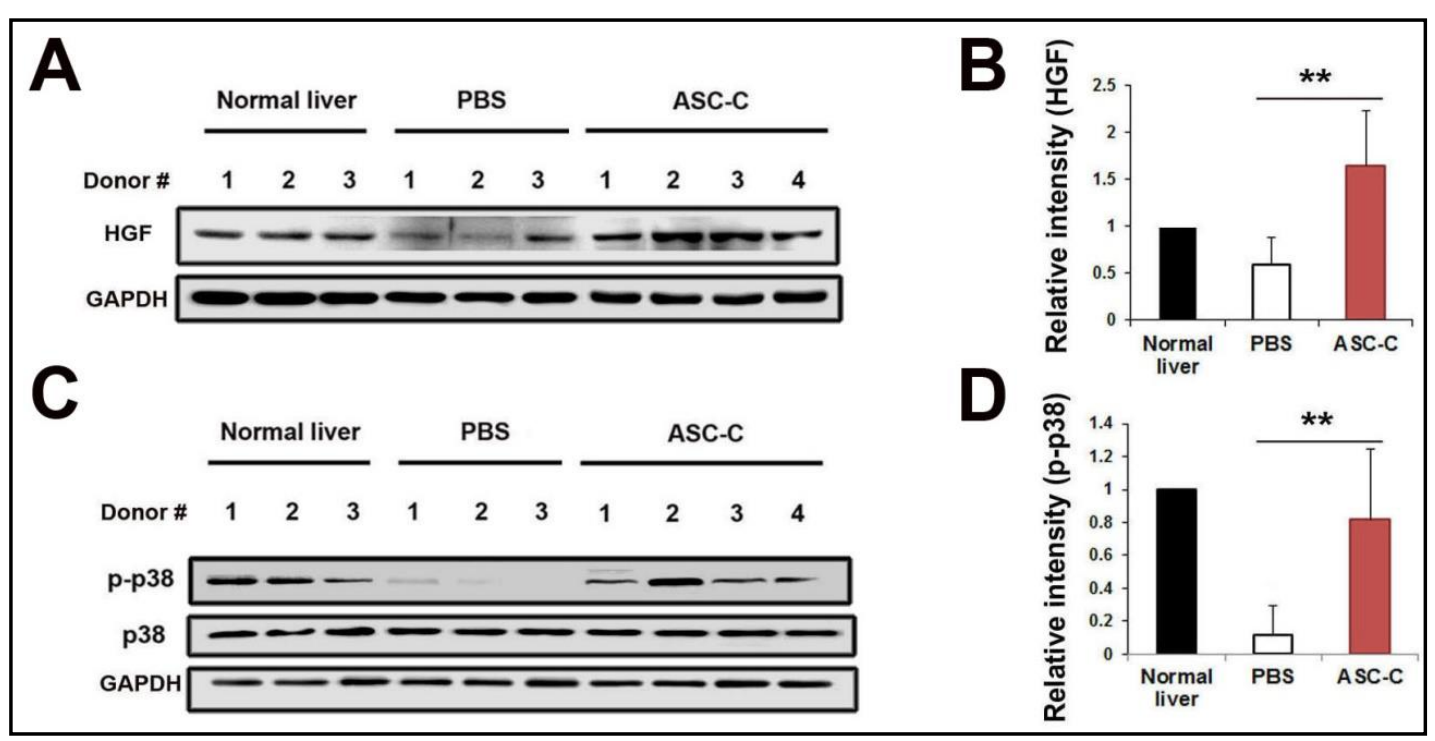

Fig. 12. ASC-C promote liver regeneration by HGF and the p-38 MAPK signaling pathway.(A) Western blot results of liver lysates after cell injection. (B) Quantitative analysis of HGF protein expression in liver tissues after cell injection. ${ }^{* *} \mathrm{p}<0.01$. (C) Western blotting results of liver lysates after cell injection. The downstream signaling pathway of MAPK. (D) Quantitative analysis of HGF protein expression in the liver tissues after cell injection. ${ }^{* *} \mathrm{p}<0.01$.

also found that injected ASC-C engrafted in liver tissue and they were expressing hepatocyte specific markers CK-18 and CK-19 (Supplementary Fig. 6A and 6B). These results indicate that ASC-C may have multipotent transdifferentiation potentials.

\section{HGF promotes hepatocyte regeneration via the $p 38$ MAPK pathway}

To further investigate the cause of hepatocyte regeneration, we performed western blotting using ASC-C-transplanted liver tissues. The expression of human HGF protein was increased in the ASC-C-injected liver tissues (Fig. 12A and 12B), suggesting that HGF acts as a priming factor to regenerate hepatocytes. In addition, p38 mitogen-activated protein kinase (MAPK) was markedly phosphorylated in the ASC-C-injected liver tissues (Fig. 12C and 12D). However, we could not detect phosphorylation of p38 MAPK in the PBS-treated liver tissues. Taken together, these data suggest that the mechanism of liver regeneration is through the activation of the p38 MAPK signal pathway via HGF derived from ASC-C.

\section{Discussion}

Currently, several clinical or pre-clinical studies on liver diseases have investigated the use of MSCs as a potential treatment strategy. The therapeutic mechanisms of their beneficial effects are mediated by their anti-fibrotic effect and their beneficial function in hepatocyte differentiation and regeneration [20-22]. The main aim of this study was to enhance the therapeutic effect of MSCs through hepatic regeneration or anti-fibrotic mechanisms. In this study, we reported for the first time that a novel cytokine cocktail promoted the expression of hepatic growth factor in ASCs, and we analyzed the subsequent therapeutic mechanism in an animal model of liver cirrhosis.

Numerous pre-clinical studies have demonstrated effective therapy of liver fibrosis and cirrhosis using MSCs [23, 24]. However, Carvalho et al. reported that MSCs have low therapeutic effects in improving liver function or reducing liver fibrosis [25]. In addition, a recent clinical study evaluated the use of autologous MSCs in a randomized, placebocontrolled trial in cirrhosis and found no beneficial effect, and other clinical studies also 
showed no convincing benefit from the use of various autologous cells in liver disease [26]. These controversial results prompted us to enhance the therapeutic function of MSCs for the treatment of liver disease.

HGF is known as a paracrine cellular growth factor that primarily acts on epithelial cells, endothelial cells, hematopoietic progenitor cells and T cells. HGF regulates cell growth, cell motility and morphogenesis by activating a tyrosine kinase signaling cascade through the c-Met receptor [27] and has a central role in angiogenesis and the development and regeneration of livers by stimulating cell motility, mitogenesis and matrix invasion [27, 28]. HGF also leads to the induction of hepatic stellate cell apoptosis, which is associated with its anti-fibrotic effect [29]. These surprising beneficial effects of HGF triggered many studies to investigate HGF overexpression in stem cells. In fact, adenoviral vector-mediated transduction of human HGF in bone marrow MSCs resulted not only in the reduction of liver fibrosis but also in the functional improvement of hepatocytes [30]. In addition, MSCs overexpressing HGF prevented liver failure and reduced mortality, and transplanted MSCs incorporated into liver remnants and produced albumin [8]. However, although genetically modified MSCs have shown high therapeutic effects, the method of genetic manipulation has the potential risk of activating oncogenes. Therefore, we attempted to enhance HGF expression in MSCs without genetic modifications.

For many years, our laboratory has been investigating safe methods to effectively induce the angiogenic or tissue regenerative potential of stem or progenitor cells without genetic modification. Previously, we reported that differentiated stem or progenitor cells induced by specific growth factor cocktails exhibit high levels of angiogenic factors such as Ang-1, HGF, FGF-2, PDGF and PLGF [15, 31]. Thus, we hypothesized that a certain growth factor cocktail might induce specific angiogenic factors in ASCs. Intriguingly, we found that the combination of four growth factors markedly enhanced the level of HGF, IGFBP-2, IL-8 and G-CSF in ASCs within only five days. It has been reported that FGF-2 induces HGF expression via the c-Jun $\mathrm{N}$-terminal kinase (JNK) signaling pathway in ASCs [12]. We compared the expression of HGF in cells treated with FGF-2 alone with those treated with the four growth factor cocktails, including FGF-2. Interestingly, the four growth factor cocktail-treated ASCs show a higher level of HGF expression, indicating that the four growth factors had a synergistic effect to enhance stem cell function for the treatment of damaged liver. We also observed another interesting effect, which was the high cell proliferation activity in ASC-C. It has been reported that FGF-2 promotes the proliferation of MSCs by activating the PI3K and the ERK signaling pathways [32]. EGF has also been shown to induce the proliferation of human MSCs [33], suggesting that dual treatment with FGF-2 and EGF might synergistically induce proliferation in ASCs.

A recent report has demonstrated that ASCs secrete high levels of interleukin-1 receptor (IL-1R), IL-6, IL-8, granulocyte colony-stimulating factor (G-CSF), granulocyte-macrophage colony-stimulating factor (GM-CSF), monocyte chemotactic protein-1 (MCP-1), nerve growth factor (NGF), and HGF [2]. Among these factors, IL-8 (CXCL8) was highly upregulated in ASC-C. In fact, HGF-induced activation of MEK and PI3K signal pathways promotes the expression of the pro-angiogenic cytokine, IL-8 [34]. High levels of expression of HGF in ASC-C might have increased IL-8 expression in an autocrine manner. One of the interesting findings of this study is the enriched chemokine expression of ASC-C. Recently, it has been reported that CXC chemokines regulate hepatocyte proliferation and liver regeneration and have hepatoprotective effects [35-37]. Our data and reports from others indicate that CXC ligands from ASC-C may promote hepatocyte proliferation in cirrhotic livers. We also observed high levels of expression of IGFBP-2, TNF- $\alpha$, SCF, G-CSF and LIF in ASC-C. Specifically, the 50 -fold higher expression of IGFBP in the microarray data was intriguing. IGFBP regulates insulinlike growth factor (IGF)-1 as a carrier protein [38], indicating the possible anti-apoptotic role of IGFBP in the reduction of liver injury upon treatment with ASC-C. Anti-apoptotic effect of IGFBP also has been reported that IGFBP directly prevents the conversion of pro-caspase-3 into caspase-3 [39]. In line with our observation, it also has been demonstrated that high expression of IGFBP in MSCs could reverse fulminant hepatic failure [37] or decrease liver 


\section{Cellular Physiology Cell Physiol Biochem 2019;52:935-950 \\ \begin{tabular}{ll|l} 
and Biochemistry $\begin{array}{l}\text { DOl: 10.33594/000000065 } \\
\text { Published online: } 10 \text { April 2019 }\end{array}$ & $\begin{array}{l}\text { O } 2019 \text { The Author(s). Published by } \\
\text { Cell Physiol Biochem Press GmbH\&Co. KG }\end{array}$ \\
\cline { 2 - 3 } &
\end{tabular} \\ Choi et al.: Generation of Induced Hepatogenic Stem Cells}

fibrosis [20]. TNF- $\alpha$ has been shown to promote regenerative responses to liver injury [40]. SCF is one of the candidate cytokines involved in hepatic remodeling by hepatocyte proliferation [41]. Additionally, G-CSF has also been noted to be involved in hepatic repair and regeneration by promoting endogenous repair mechanisms [42].

Adipose tissues are one of the most attractive sources of stem cell due to their high accessibility, mesenchymal progenitor cell abundance and minimal invasiveness for autologous cell therapy. In addition, it has been noted that ASCs have a particular affinity for hepatocyte differentiation in vitro and liver regeneration in vivo [43]. Although we did not aim to induce ASC differentiation into hepatocytes in the present study, we have verified the hepatocyte-like properties of ASC-C during the cytokine stimulation period. Interestingly, we detected high levels of expression of hepatocyte proteins, such as AFP, ALB, CK18, CK19 and HGF, in ASC-C (D5) compared with those in ASCs and ASC-b. These results indicate that the four growth factors might be an excellent combination for inducing ASCs into hepatocyte-like cells within a short period of 5 days. As a recent publication demonstrated that hepatic differentiated MSCs show superior therapeutic effects on liver damage than non-differentiated MSCs [44], ASC-C might possess a high therapeutic potential.

Although it has been reported that FGF induces the secretion of HGF in ASCs, their therapeutic effect in liver cirrhotic models has not been fully understood. As HGF plays an important role in regenerating hepatocytes, we speculated that high levels of HGFexpressing ASCs might have enhanced therapeutic effects in liver cirrhosis. In fact, we found that conditioned medium from ASC-C markedly inhibited the activation of HSCs in vitro (Fig. 5A, 5B and 5C). To investigate whether these properties persisted in vivo, we performed cell transplantation studies using a liver injury nude mouse model. In accordance with the in vitro data, the therapeutic effect of ASC-C injection was superior to the injection of untreated ASCs, showing reduced liver fibrosis and accelerating the recovery of liver function. These anti-fibrosis effects can be elucidated by the mechanism associating with the upregulation of ECM remodeling factor, MMP-13, which degrades interstitial collagen and plays candidates for an anti-fibrotic role. Since its overexpression showed significant decreased liver fibrosis and enhanced hepatocyte proliferation [45].

It has been reported that humoral factors from MSCs ameliorate acute or chronic liver failure [46]. Thus, we elucidated the therapeutic mechanism of the humoral factors released from ASC-C. Interestingly, high numbers of Ki-67 positive hepatocytes were observed in the ASC-C-treated group compared with the PBScontrol group, indicating accelerated liver regeneration. In the grafted liver tissues, HGF and the p38 MAPK pathway were also activated in the ASC-C-transplanted group, suggesting that HGF is one of the representative humoral factors for hepatocyte proliferation. These data are in line with previous studies, showing that the activation of p38 MAPK is a prerequisite for hepatocyte proliferation [47] and HGF induced cell proliferation [48]. Another possible therapeutic mechanism contributing to liver regeneration might be the angiogenic property of the transplanted ASC-C. Transplantation of ASC-C promoted capillary density in liver tissues. High levels of humoral factors, such as HGF and IL-8, which are also known to promote angiogenesis and neovascularization [49], secreted from ASC-C might exert these beneficial effects on the cirrhotic liver. As transdifferentiation could be another therapeutic mechanism of the transplanted stem cells, we traced the fate of the injected ASC-C in vivo. Interestingly, some of the endothelial differentiated ASC-C were engrafted in the perivascular area of the liver tissue. Additionally, we found engrafted human ALB, CK18 and CK19-expressing ASC-C in the mouse livers. These data indicate that ASC-C might possess mutiple transdifferentiation capacity, and these properties might enhance liver regeneration. 


\section{Cellular Physiology Cell Physiol Biochem 2019;52:935-950

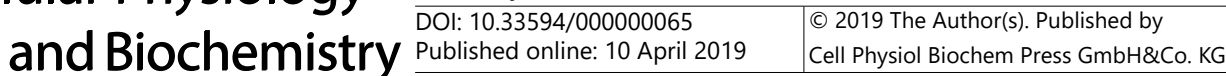 \\ Choi et al.: Generation of Induced Hepatogenic Stem Cells}

\section{Conclusion}

A novel cytokine combination stimulated ASCs to exhibit robust hepatogenic and angiogenic capacities that ameliorated liver cirrhosis. Accordingly, ASC-C might be a highly promising and novel therapeutic alternative for treating liver cirrhosis. Further investigation will be required to demonstrate whether ASC-C are capable of treating liver cirrhosis in clinical trials.

\section{Acknowledgements}

This study was supported by National Research Foundation of Korea grants funded by the Korean government (no. NRF-2016R1A2B4012683 and no. NRF-2015M3A9E6029558) and the research fund of Catholic Kwandong University for Dr. S.-W Kim; the National Research Foundation of Korea(NRF) grant funded by the Korea government (MSIT) (No. 2018R1C1B5041259) for Dr. J.S Choi.

Although this study demonstrated the therapeutic effects of ASC-C, relatively low number of mice and short time period of follow-up might be study limitations.

Conceived and designed the experiments: S-WK. Performed major experiments: HAR, JSC. Analyzed the data: JSC, S-WK. Contributed reagents/materials/analysis tools: JSC, SHC. Wrote the paper: S-WK.

\section{Disclosure Statement}

The authors declare to have no competing interests.

\section{References}

1 Alcolado R, Arthur MJ, Iredale JP: Pathogenesis of liver fibrosis. Clin Sci (Lond) 1997;92:103-112.

- 2 Banas A, Teratani T, Yamamoto Y, Tokuhara M, Takeshita F, Osaki M, Kawamata M, Kato T, Okochi H, Ochiya T: IFATS collection: in vivo therapeutic potential of human adipose tissue mesenchymal stem cells after transplantation into mice with liver injury. Stem Cells 2008;26:2705-2712.

- 3 Zhang D, Jiang M, Miao D: Transplanted human amniotic membrane-derived mesenchymal stem cells ameliorate carbon tetrachloride-induced liver cirrhosis in mouse. PLoS One 2011;6:e16789.

- 4 Roos F, Terrell TG, Godowski PJ, Chamow SM, Schwall RH: Reduction of alpha-naphthylisothiocyanateinduced hepatotoxicity by recombinant human hepatocyte growth factor. Endocrinology 1992;131:25402544.

- 5 Ishiki Y, Ohnishi H, Muto Y, Matsumoto K, Nakamura T: Direct evidence that hepatocyte growth factor is a hepatotrophic factor for liver regeneration and has a potent antihepatitis effect in vivo. Hepatology 1992;16:1227-1235.

- 6 Morita M, Watanabe Y, Akaike T: Protective effect of hepatocyte growth factor on interferon-gammainduced cytotoxicity in mouse hepatocytes. Hepatology 1995;21:1585-1593.

- 7 Yao P, Zhan Y, Xu W, Li C, Yue P, Xu C, Hu D, Qu CK, Yang X: Hepatocyte growth factor-induced proliferation of hepatic stem-like cells depends on activation of NF-kappaB. J Hepatol 2004;40:391-398.

8 Yu Y, Yao AH, Chen N, Pu LY, Fan Y, Lv L, Sun BC, Li GQ, Wang XH: Mesenchymal stem cells over-expressing hepatocyte growth factor improve small-for-size liver grafts regeneration. Mol Ther 2007;15:1382-1389.

9 Quarto N, Longaker MT: FGF-2 inhibits osteogenesis in mouse adipose tissue-derived stromal cells and sustains their proliferative and osteogenic potential state. Tissue Eng 2006;12:1405-1418.

- 10 Kang YJ, Jeon ES, Song HY, Woo JS, Jung JS, Kim YK, Kim JH: Role of c-Jun N-terminal kinase in the PDGFinduced proliferation and migration of human adipose tissue-derived mesenchymal stem cells. J Cell Biochem 2005;95:1135-1145. 


\section{Cellular Physiology Cell Physiol Biochem 2019;52:935-950 \begin{tabular}{ll|l|l|}
\hline DOl: $10.33594 / 000000065$ & O 2019 The Author(s). Published by \\
and Biochemistry
\end{tabular} and Biochemistry Published online: 10 April 2019 Cell Physiol Biochem Press GmbH\&Co. KG \\ Choi et al.: Generation of Induced Hepatogenic Stem Cells}

- 11 Suga H, Shigeura T, Matsumoto D, Inoue K, Kato H, Aoi N, Murase S, Sato K, Gonda K, Koshima I, Yoshimura K: Rapid expansion of human adipose-derived stromal cells preserving multipotency. Cytotherapy 2007;9:738-745.

- 12 Suga H, Eto H, Shigeura T, Inoue K, Aoi N, Kato H, Nishimura S, Manabe I, Gonda K, Yoshimura K: IFATS collection: Fibroblast growth factor-2-induced hepatocyte growth factor secretion by adipose-derived stromal cells inhibits postinjury fibrogenesis through a c-Jun N-terminal kinase-dependent mechanism. Stem Cells 2009;27:238-249.

13 Kim SW, Kim H, Cho HJ, Lee JU, Levit R, Yoon YS: Human peripheral blood-derived CD31 + cells have robust angiogenic and vasculogenic properties and are effective for treating ischemic vascular disease. J Am Coll Cardiol 2010;56:593-607.

14 Kim SW, Zhang HZ, Guo L, Kim JM, Kim MH: Amniotic mesenchymal stem cells enhance wound healing in diabetic NOD/SCID mice through high angiogenic and engraftment capabilities. PLoS One 2012;7:e41105.

15 Kim SW, Houge M, Brown M, Davis ME, Yoon YS: Cultured human bone marrow-derived CD31(+) cells are effective for cardiac and vascular repair through enhanced angiogenic, adhesion, and anti-inflammatory effects. J Am Coll Cardiol 2014;64:1681-1694.

16 Youn YJ, Yoo BS, Son JW, Lee JW, Ahn MS, Ahn SG, Kim JY, Lee SH, Yoon J, Eom YW, Oh JE, Choi SK: Remote Ischemic Conditioning by Effluent Collected from a Novel Isolated Hindlimb Model Reduces Infarct Size in an Isolated Heart Model. Korean Circ J 2017;47:714-726.

- 17 Eom YW, Jung HY, Oh JE, Lee JW, Ahn MS, Youn YJ, Ahn SG, Kim JY, Lee SH, Yoon J, Yoo BS: Isoproterenol Enhances Tumor Necrosis Factor-Related Apoptosis-Inducing Ligand-Induced Apoptosis in Human Embryonic Kidney Cells through Death Receptor 5 up-Regulation. Korean Circ J 2016;46:93-98.

18 Tang WP, Akahoshi T, Piao JS, Narahara S, Murata M, Kawano T, Hamano N, Ikeda T, Hashizume M: Basic fibroblast growth factor-treated adipose tissue-derived mesenchymal stem cell infusion to ameliorate liver cirrhosis via paracrine hepatocyte growth factor. J Gastroenterol Hepatol 2015;30:1065-1074.

19 Arthur MJ: Fibrogenesis II. Metalloproteinases and their inhibitors in liver fibrosis. Am J Physiol Gastrointest Liver Physiol 2000;279:G245-249.

20 Meier RP, Mahou R, Morel P, Meyer J, Montanari E, Muller YD, Christofilopoulos P, Wandrey C, GonelleGispert C, Buhler LH: Microencapsulated human mesenchymal stem cells decrease liver fibrosis in mice. J Hepatol 2015;62:634-641.

21 Sato Y, Araki H, Kato J, Nakamura K, Kawano Y, Kobune M, Sato T, Miyanishi K, Takayama T, Takahashi M, Takimoto R, Iyama S, Matsunaga T, Ohtani S, Matsuura A, Hamada H, Niitsu Y: Human mesenchymal stem cells xenografted directly to rat liver are differentiated into human hepatocytes without fusion. Blood 2005;106:756-763.

- 22 Feng J, Mantesso A, De Bari C, Nishiyama A, Sharpe PT: Dual origin of mesenchymal stem cells contributing to organ growth and repair. Proc Natl Acad Sci U S A 2011;108:6503-6508.

23 Fang B, Shi M, Liao L, Yang S, Liu Y, Zhao RC: Systemic infusion of FLK1(+) mesenchymal stem cells ameliorate carbon tetrachloride-induced liver fibrosis in mice. Transplantation 2004;78:83-88.

24 Sakaida I, Terai S, Yamamoto N, Aoyama K, Ishikawa T, Nishina H, Okita K: Transplantation of bone marrow cells reduces CCl4-induced liver fibrosis in mice. Hepatology 2004;40:1304-1311.

25 Carvalho AB, Quintanilha LF, Dias JV, Paredes BD, Mannheimer EG, Carvalho FG, Asensi KD, Gutfilen B, Fonseca LM, Resende CM, Rezende GF, Takiya CM, de Carvalho AC, Goldenberg RC: Bone marrow multipotent mesenchymal stromal cells do not reduce fibrosis or improve function in a rat model of severe chronic liver injury. Stem Cells 2008;26:1307-1314.

26 Moore JK, Stutchfield BM, Forbes SJ: Systematic review: the effects of autologous stem cell therapy for patients with liver disease. Aliment Pharmacol Ther 2014;39:673-685.

27 Bottaro DP, Rubin JS, Faletto DL, Chan AM, Kmiecik TE, Vande Woude GF, Aaronson SA: Identification of the hepatocyte growth factor receptor as the c-met proto-oncogene product. Science 1991;251:802-804.

28 Bussolino F, Di Renzo MF, Ziche M, Bocchietto E, Olivero M, Naldini L, Gaudino G, Tamagnone L, Coffer A, Comoglio PM: Hepatocyte growth factor is a potent angiogenic factor which stimulates endothelial cell motility and growth. J Cell Biol 1992;119:629-641.

29 Kodama T, Takehara T, Hikita H, Shimizu S, Li W, Miyagi T, Hosui A, Tatsumi T, Ishida H, Tadokoro S, Ido A, Tsubouchi H, Hayashi N: Thrombocytopenia exacerbates cholestasis-induced liver fibrosis in mice. Gastroenterology 2010; DOI:10.1053/j.gastro.2010.02.054. 


\section{Cellular Physiology Cell Physiol Biochem 2019;52:935-950 \begin{tabular}{ll|l|}
\cline { 2 - 2 } DOI: 10.33594/000000065 & O 2019 The Author(s). Published by \\
\hline
\end{tabular} and Biochemistry Published online: 10 April 2019 Cell Physiol Biochem Press GmbH\&Co. KG \\ Choi et al.: Generation of Induced Hepatogenic Stem Cells}

- 30 Kim MD, Kim SS, Cha HY, Jang SH, Chang DY, Kim W, Suh-Kim H, Lee JH: Therapeutic effect of hepatocyte growth factor-secreting mesenchymal stem cells in a rat model of liver fibrosis. Exp Mol Med 2014;46:e110.

- 31 Choi B, Chun E, Kim M, Kim SY, Kim ST, Yoon K, Lee KY, Kim SJ: Human T cell development in the liver of humanized NOD/SCID/IL-2Rgamma(null)(NSG) mice generated by intrahepatic injection of CD34(+) human (h) cord blood (CB) cells. Clin Immunol 2011;139:321-335.

- 32 Choi SC, Kim SJ, Choi JH, Park CY, Shim WJ, Lim DS: Fibroblast growth factor-2 and -4 promote the proliferation of bone marrow mesenchymal stem cells by the activation of the PI3K-Akt and ERK1/2 signaling pathways. Stem Cells Dev 2008;17:725-736.

33 Tamama K, Fan VH, Griffith LG, Blair HC, Wells A: Epidermal growth factor as a candidate for ex vivo expansion of bone marrow-derived mesenchymal stem cells. Stem Cells 2006;24:686-695.

34 Dong G, Chen Z, Li ZY, Yeh NT, Bancroft CC, Van Waes C: Hepatocyte growth factor/scatter factor-induced activation of MEK and PI3K signal pathways contributes to expression of proangiogenic cytokines interleukin-8 and vascular endothelial growth factor in head and neck squamous cell carcinoma. Cancer Res 2001;61:5911-5918.

35 Wilson GC, Kuboki S, Freeman CM, Nojima H, Schuster RM, Edwards MJ, Lentsch AB: CXC chemokines function as a rheostat for hepatocyte proliferation and liver regeneration. PLoS One 2015;10:e0120092.

- 36 Van Sweringen HL, Sakai N, Tevar AD, Burns JM, Edwards MJ, Lentsch AB: CXC chemokine signaling in the liver: impact on repair and regeneration. Hepatology 2011;54:1445-1453.

- 37 Parekkadan B, van Poll D, Suganuma K, Carter EA, Berthiaume F, Tilles AW, Yarmush ML: Mesenchymal stem cell-derived molecules reverse fulminant hepatic failure. PLoS One 2007;2:e941.

38 Kelley KM, Oh Y, Gargosky SE, Gucev Z, Matsumoto T, Hwa V, Ng L, Simpson DM, Rosenfeld RG: Insulinlike growth factor-binding proteins (IGFBPs) and their regulatory dynamics. Int J Biochem Cell Biol 1996;28:619-637.

- 39 Taub R: Liver regeneration: from myth to mechanism. Nat Rev Mol Cell Biol 2004;5:836-847.

- 40 Diehl AM, Yin M, Fleckenstein J, Yang SQ Lin HZ, Brenner DA, Westwick J, Bagby G, Nelson S: Tumor necrosis factor-alpha induces c-jun during the regenerative response to liver injury. Am J Physiol 1994;267:G552-561.

41 Ren X, Hu B, Colletti L: Stem cell factor and its receptor, c-kit, are important for hepatocyte proliferation in wild-type and tumor necrosis factor receptor-1 knockout mice after $70 \%$ hepatectomy. Surgery 2008;143:790-802.

- 42 Yannaki E, Athanasiou E, Xagorari A, Constantinou V, Batsis I, Kaloyannidis P, Proya E, Anagnostopoulos A, Fassas A: G-CSF-primed hematopoietic stem cells or G-CSF per se accelerate recovery and improve survival after liver injury, predominantly by promoting endogenous repair programs. Exp Hematol 2005;33:108119.

- 43 Banas A, Teratani T, Yamamoto Y, Tokuhara M, Takeshita F, Osaki M, Kato T, Okochi H, Ochiya T: Rapid hepatic fate specification of adipose-derived stem cells and their therapeutic potential for liver failure. J Gastroenterol Hepatol 2009;24:70-77.

44 Itaba N, Matsumi Y, Okinaka K, Ashla AA, Kono Y, Osaki M, Morimoto M, Sugiyama N, Ohashi K, Okano T, Shiota G: Human mesenchymal stem cell-engineered hepatic cell sheets accelerate liver regeneration in mice. Sci Rep 2015;5:16169.

45 Endo H, Niioka M, Sugioka Y, Itoh J, Kameyama K, Okazaki I, Ala-Aho R, Kahari VM, Watanabe T: Matrix metalloproteinase-13 promotes recovery from experimental liver cirrhosis in rats. Pathobiology 2011;78:239-252.

46 Kuo TK, Hung SP, Chuang CH, Chen CT, Shih YR, Fang SC, Yang VW, Lee OK: Stem cell therapy for liver disease: parameters governing the success of using bone marrow mesenchymal stem cells. Gastroenterology 2008; DOI:10.1053/j.gastro.2008.03.015.

- 47 Spector MS, Auer KL, Jarvis WD, Ishac EJ, Gao B, Kunos G, Dent P: Differential regulation of the mitogenactivated protein and stress-activated protein kinase cascades by adrenergic agonists in quiescent and regenerating adult rat hepatocytes. Mol Cell Biol 1997;17:3556-3565.

- 48 Awasthi V, King RJ: PKC, p42/p44 MAPK, and p38 MAPK are required for HGF-induced proliferation of H441 cells. Am J Physiol Lung Cell Mol Physiol 2000;279:L942-949.

49 Kumar R, Yoneda J, Bucana CD, Fidler IJ: Regulation of distinct steps of angiogenesis by different angiogenic molecules. Int J Oncol 1998;12:749-757. 